\title{
Response to 'Statins accelerate the onset of collagen type Il-induced arthritis in mice' - authors' reply
}

\author{
Rob J Vandebriel ${ }^{* 1}$, Hilda JI De Jong ${ }^{1,2,3}$, Eric R Gremmer', Olaf H Klungel ${ }^{3}$, Jan-Willem Cohen Tervaert ${ }^{4}$, Wout Slob5, \\ Jan Willem Van Der Laan ${ }^{6}$ and Henk Van Loveren ${ }^{1,2}$ \\ See related research by Vandebriel et al., http://arthritis-research.com/content/14/2/R90, and related letter by Mathieu et al., \\ http://arthritis-research.com/content/15/2/402
}

We thank Mathieu and colleagues for their interest in our recent publication [1] and for reporting their very interesting experiments showing that intraperitoneal but not subcutaneous simvastatin inhibits arthritis progression in the mouse collagen-induced arthritis (CIA) model [2]. These results are in line with those of Palmer and colleagues, who showed that intraperitoneal but not oral simvastatin administration inhibited pre-existing CIA [3].

According to Mathieu and colleagues, in our study we found that 'oral atorvastatin and pravastatin had no effect on the arthritis score after CIA induction' [2]. This statement is not correct, however. In our study, the number of arthritic animals increased from seven out of 12 in the nonstatin-treated controls to 12 out of 12 animals given oral atorvastatin and pravastatin, both after CIA induction (Figure 3A in [1]). Moreover, the summed arthritis score increased from 21 in the nonstatin-treated controls to 37 for oral pravastatin and 49 for oral atorvastatin, both after CIA induction (Figure 3B in [1]).

Since our aim was to investigate the possible effects of statin intake upon arthritis development and severity, we chose to administer statins orally - the common route of administration for patients receiving statins. The findings from Mathieu and colleagues [2] underscore that statins have an immunomodulatory activity. Altogether, one may conclude that the outcome of statins on immune responses may depend on the type of statin, the dose, and the route of administration. Whereas we acknowledge that statins may have beneficial immunological effects,

\footnotetext{
*Correspondence: rob.vandebriel@rivm.nl

'Laboratory for Health Protection Research, National Institute for Public Health and the Environment, Antonie van Leeuwenhoeklaan 9, PO Box 1, 3720 BA Bilthoven, the Netherlands

Full list of author information is available at the end of the article
}

statins may also play a role in the induction of autoimmunity, as we have also shown in a general population-based study [4].

\section{Abbreviations}

CIA, collagen-induced arthritis.

\section{Competing interests}

The authors declare that they have no competing interests.

\section{Author details}

'Laboratory for Health Protection Research, National Institute for Public Health and the Environment, Antonie van Leeuwenhoeklaan 9, PO Box 1, 3720 BA Bilthoven, the Netherlands. ${ }^{2}$ Department of Toxicogenomics, Maastricht University, Universiteitssingel 50, PO Box 616, 6200 MD Maastricht, the Netherlands. ${ }^{3}$ Division of Pharmacoepidemiology and Clinical Pharmacology, Utrecht Institute for Pharmaceutical Sciences, Utrecht University, Universiteitsweg 99, PO Box 80 082, 3508 TB Utrecht, the Netherlands. ${ }^{4}$ Department of Internal Medicine, Division of Clinical and Experimental Immunology, University Hospital Maastricht, Universiteitssingel 50, PO Box 616, 6200 MD Maastricht, the Netherlands. ${ }^{5}$ Centre for Substances and Integrated Risk Assessment, National Institute for Public Health and the Environment, Antonie van Leeuwenhoeklaan 9, PO Box 1, 3720 BA Bilthoven, the Netherlands. ${ }^{6}$ Section on Pharmacology, Toxicology and Biotechnology (FTBB), Medicines Evaluation Board, Graadt van Roggenweg 500, PO Box 8275 , 3503 RG Utrecht, the Netherlands.

Published: 8 March 2013

\section{References}

1. Vandebriel RJ, De Jong HJ, Gremmer ER, Klungel OH, Cohen Tervaert JW, Slob W, Van Der Laan JW, Van Loveren H: Statins accelerate the onset of collagen type II-induced arthritis in mice. Arthritis Res Ther 2012, 14:R90.

2. Mathieu S, Palat S, Pereira B, Kemeny JL, Marceau G, Dubray C, Soubrier M: Response to 'Statins accelerate the onset of collagen type II-induced arthritis in mice'. Arthritis Res Ther 2013, 15:402.

3. Palmer G, Chobaz V, Talabot-Ayer D, Taylor S, So A, Gabay C, Busso N: Assessment of the efficacy of different statins in murine collagen induced arthritis. Arthritis Rheum 2004, 50:4051-4059.

4. De Jong HJ, Klungel OH, van Dijk L, Vandebriel RJ, Leufkens HG, Van Der Laan J, Tervaert JW, Van Loveren $\mathrm{H}$ : Use of statins is associated with an increased risk of rheumatoid arthritis. Ann Rheum Dis 2012, 71:648-654.

\section{doi:10.1186/ar4170}

Cite this article as: Vandebriel RJ, et al.: Response to 'Statins accelerate the onset of collagen type II-induced arthritis in mice' - authors' reply. Arthritis Research \& Therapy 2013, 15:403. 